\title{
Novos TEMPOS E NOVOS DESAFIOS EDUCACIONAIS: A EDUCAÇÃO BÁSICA NA MODALIDADE REMOTA DURANTE A PANDEMIA DE COVID-19
}

\author{
NEW TIMES AND NEW EDUCATIONAL CHALLENGES: BASIC EDUCATION IN REMOTE \\ MODALITY DURING THE COVID-19 PANDEMIC
}

NUEVOS TIEMPOS Y NUEVOS RETOS EDUCATIVOS: LA EDUCACIÓN BÁSICA EN LA MODALIDAD REMOTA DURANTE LA PANDEMIA COVID-19

\author{
Elton Castro Rodrigues dos \\ Santos \\ (iD) 9 \\ Doutorado em Educação (UNESP) \\ Professor da Faculdade do \\ Cooperativismo (ICOOP) \\ elton.castro@unemat.br
}

\section{Marineide de Oliveira da \\ Silva \\ (iD) 9}

Doutorado em Educação (UNESP)

Professora do Instituto Cuiabá de

Ensino e Cultura (ICEC)

mari.oliveirasil@gmail.com

\section{Niltom Vieira Junior

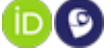

Doutorado em Engenharia Elétrica (UNESP)

Professor do Instituto Federal de

Minas Gerais (IFMG)

niltom.vieira@ifmg.edu.br

\begin{abstract}
Resumo
A tecnologia tem sido uma aliada importante da educação básica em tempos pandêmicos, mas ainda há professores e alunos com dificuldade de adaptação a essa nova realidade. Por isso, este trabalho, com bases bibliográficas, tem o objetivo de apresentar e debater questões que envolvem a problemática do ensino remoto na educação básica, incluindo limites e possibilidades de sucesso educacional nessa modalidade. O levantamento bibliográfico mostrou que, embora o Brasil seja um país que consome um grande número de recursos tecnológicos, estes não estão sendo utilizados na educação. Além disso, constatou-se que, para que pudessem avançar nos estudos, durante o distanciamento social, professores e alunos precisaram se reinventar e, embora a situação seja controversa, acredita-se que a prática das aulas remotas trará benefícios futuros, pois teremos professores com maior expertise no uso das tecnologias, o que pode fazer com que surja, no ensino presencial, aulas mais dinâmicas e interativas.
\end{abstract}

Palavras-chave: Educação básica. Ensino remoto. Tecnologia.

Recebido em: 23 de abril de 2021 .

Aprovado em: 18 de julho de 2021.

Como citar esse artigo (ABNT):

SANTOS, Elton Castro Rodrigues dos; SILVA, Marineide de Oliveira da; VIEIRA JUNIOR, Niltom. Novos tempos e novos desafios educacionais: a educação básica na modalidade remota durante a pandemia de Covid-19. Revista Prática Docente, v. 6, n. 2, e056, 2021.

http://doi.org/10.23926/RPD.2021.v6.n2.e056.id1185 


\section{Abstract}

Technology has been an important ally for Basic Education in pandemic times, but there still are teachers and students with difficulties to adapt to this new reality. Hence, through its bibliographic bases, this study intends to present and debate questions related to the problematic of the remote teaching in Basic Education, including the limits and possibilities of educational success in that modality. The bibliographic survey showed that, although Brazil is a country that consumes a great number of technological resources, those have not being used in education. Furthermore, we verified that, in order to progress in the studies during social distancing, teachers and students had to reinvent themselves and, although the situation is controversial, it is believed that the practice of remote classes will bring future benefits, since we will have teachers with more expertise in the use of technologies. This occasion may then create more dynamic and interactive classes in the in-person teaching.

Keywords: Basic education. Remote teaching. Technology.

\section{Resumen}

La tecnología ha sido una aliada importante para la Educación Básica en tiempos pandémicos, pero aún hay profesores y alumnos con dificultades para acostumbrarse a esta nueva realidad. Por eso, este trabajo, con sus bases bibliográficas, tiene el objetivo de presentar y debatir cuestiones relacionadas con la enseñanza remota en la Educación Básica, incluyendo límites y posibilidades para el éxito educativo en esta modalidad. El estudio bibliográfico ha mostrado que, aunque el Brasil sea un país que consume un gran número de recursos tecnológicos, ellos no han sido usados en la educación. Además, se ha encontrado que, para que pudieran avanzar en los estudios durante el distanciamiento social, profesores y alumnos tuvieron que reinventarse y, aunque la situación sea polémica, se cree que la práctica de las clases remotas traerá beneficios futuros, porque tendremos profesores con mayor pericia en el uso de las tecnologías, que pueden hacer que suceda en la enseñanza presencial clases más dinámicas e interactivas.

Palabras clave: Educación Básica. Enseñanza Remota. Tecnología. 


\section{INTRODUÇÃo}

A evolução tecnológica mostra como as ferramentas de comunicação foram se modificando e se adaptando às demandas emergentes. Nesse contexto, com o surgimento da pandemia de Covid-19, o ensino, que antes era majoritariamente presencial, passou a exigir novas formas de ensinar em função da adoção da modalidade a distância e/ou remota. Vale ressaltar que o ensino a distância requer um aparato tecnológico que se difere da simples utilização do WhatsApp. Em torno do ensino a distância existem vários profissionais envolvidos cotidianamente: um grupo de coordenadores da unidade de Educação a Distância - EaD; um coordenador para cada curso oferecido pela instituição; um coordenador para cada disciplina; um grupo de professores, tutores, técnicos e monitores (MILL; FIDALGO, 2007), além da estrutura tecnológica (servidores, AVA, soft, sistemas, entre outras).

Conforme Moran (2002), a EaD pode ser considerada como uma modalidade de ensino cujo espaço físico é substituído por um espaço virtual, onde professores e alunos se conectam diariamente para a construção de conhecimento mediada pelo uso da tecnologia. Esse método de ensino pode ser efetivado via correio, rádio, televisão, telefone, entre outros; atualmente, o meio mais usado é a internet.

É importante dizer que as aulas remotas e a utilização dos meios digitais não têm como finalidade a gestão do tempo, ou o cumprimento de metas de aprendizagem, nem avaliações periódicas, as atividades no modelo remoto têm como foco principal o conteúdo das disciplinas. De acordo com Saraiva, Traversini e Lockmann (2020, p. 7), no ensino remoto, há a necessidade de "[...] um envio de evidências de desenvolvimento de atividades não avaliativas, que funcionam como uma forma de controle do uso do tempo, uma das características da disciplina. $\mathrm{Na} \mathrm{EaD}$, as atividades a serem desenvolvidas são, na maior parte das vezes, avaliações".

Percebe-se que os cenários de aprendizagem são diferentes, com finalidades educacionais também distintas. A EaD não tem como foco a educação básica, mas sim o ensino técnico, o tecnólogo, a graduação e a pós-graduação. Já a educação remota se constitui como uma opção para o desenvolvimento das atividades educacionais pertencentes à educação básica. Por isso, no debate dos novos desafios educacionais da educação básica na modalidade remota, é necessário distinguir tais modalidades.

Dessa forma, como objetivo a ser atingido nesta pesquisa, optou-se por apresentar e debater as questões que envolvem a problemática do ensino remoto na educação básica, seus limites e possibilidades de sucesso educacional. Na pesquisa bibliográfica levantada para o 
presente trabalho, foram analisados diversos sites, jornais, livros, teses, dissertações, periódicos, anais de eventos, entre outros textos que elucidassem a problemática proposta.

É importante lembrar ainda que a educação básica possui prerrogativas diferentes das do ensino técnico e superior, bem como da pós-graduação, por isso, deve-se ter extrema cautela para que os objetivos educacionais não sejam negligenciados. Esse nível de ensino, o da educação básica, é primordial para a base educacional que acompanhará a vida escolar do sujeito e do futuro cidadão. Diante dessa questão, justifica-se, pois, a abertura de um espaço de reflexão e debate na busca pela qualidade das atividades pedagógicas em novos tempos educacionais.

\section{A DIFERENÇA ENTRE A EdUCAÇÃO A DiSTÂNCIA (EAD) E O ENSINO REMOTO}

Segundo Yonezawa (2013), instituições como o Instituto Monitor e o Instituto Universal Brasileiro foram os pioneiros na modalidade de ensino a distância no Brasil. Esses institutos atuaram na história do ensino a distância no país durante a fase em que se enviava os materiais pelos correios, ou seja, na fase dos chamados cursos por correspondências. Esses cursos constituíram, dessa forma, o impulso inicial para a realidade atual do ensino a distância e para as oportunidades de acesso que encontramos nessa modalidade hoje em dia.

A evolução da EaD, conforme Moore e Kearsley (1996), teve a evolução das formas de comunicação como sua maior aliada, como podemos observar no quadro abaixo:

Quadro 1 - Gerações da EaD

\begin{tabular}{|c|l|}
\hline Gerações & \multicolumn{1}{c|}{ Transformações na EAD } \\
\hline $\mathbf{1}^{\mathbf{a}}$ & $\begin{array}{l}\text { Estudo por correspondência, utilizando material impresso } \\
\text { enviado por correio. }\end{array}$ \\
\hline $\mathbf{2}^{\mathbf{a}}$ & $\begin{array}{l}\text { Utilizada nas primeiras universidades abertas da década de 70, } \\
\text { além da correspondência empregavam radiodifusão, através de } \\
\text { fitas de áudio e programas de rádio. }\end{array}$ \\
\hline $\mathbf{3}^{\mathbf{a}}$ & $\begin{array}{l}\text { Programas gravados em televisão, radiodifusão, fitas de vídeo, } \\
\text { contato telefônico, satélite, cabo e linhas de Serviço Integrado } \\
\text { de Rede Digital (ISDN). }\end{array}$ \\
\hline $\mathbf{4}^{\mathbf{a}}$ & $\begin{array}{l}\text { Fundamentado em conferências e computadores, com } \\
\text { transmissão em rede e estações de trabalho multimídia } \\
\text { (videoconferências, chats, e-mail, ambientes virtuais de ensino } \\
\text { (AVA), CD-ROM, etc.) }\end{array}$ \\
\hline
\end{tabular}

Fonte: Moore e Kearsley (1996, p.10).

No quadro acima, podemos perceber as principais transformações que desenharam a realidade da Educação a Distância a qual vivenciamos atualmente. Outro passo importante para 
a expansão da EaD no Brasil ocorreu no ano de 2005 com a aprovação do Decreto $\mathrm{n}^{\mathrm{o}}$ 5.622, que estabelece o seguinte:

Para os fins deste Decreto, caracteriza-se a educação a distância como modalidade educacional na qual a mediação didático-pedagógica nos processos de ensino e aprendizagem ocorre com a utilização de meios e tecnologias de informação e comunicação, com estudantes e professores desenvolvendo atividades educativas em lugares ou tempos diversos (BRASIL, 2005, p. 1).

As atividades educativas podem abranger diferentes níveis de escolaridade, tais como: graduação; especialização; mestrado e doutorado; sendo que "os cursos e programas a distância deverão ser projetados com a mesma duração definida para os respectivos cursos na modalidade presencial" (BRASIL, 2005, p. 1).

A expansão da $\mathrm{EaD}$ ganha, em 2006, um novo impulso com a criação do sistema Universidade Aberta do Brasil - UAB pelo Decreto ${ }^{\circ} 5.800$ de 08 de junho de 2006. Essa expansão foi articulada junto com a Coordenadoria de Aperfeiçoamento do Ensino Superior CAPES. O projeto visava

[...] a articulação e integração de um sistema nacional de educação superior a distância, em caráter experimental, visando sistematizar as ações, programas, projetos, atividades pertencentes às políticas públicas voltadas para a ampliação $\mathrm{e}$ interiorização da oferta do ensino superior gratuito e de qualidade no Brasil (UNIPAMPA, 2014).

Participaram da criação do sistema Universidade Aberta do Brasil - UAB governos federais, estaduais e municipais, universidades públicas e demais organizações interessadas na modalidade EaD. De acordo com Preti (2007, p. 1), a semente para a criação da UAB já havia sido plantada vários anos atrás:

A semente para a criação da $U A B$, podemos dizer, pode ser encontrada na implantação dos consórcios BRASILEAD (1996) e UNIREDE (2000), formados por Instituições Públicas de Ensino Superior. Buscavam uns "lócus" onde pudessem estabelecer parcerias interinstitucionais para oferta de cursos a distância, trocando saberes e experiências nessa modalidade em que todos nós estávamos "engatinhando".

Com isso, a Secretaria de Educação a Distância, unida ao Ministério da Educação MEC, "passou a chamar para si também esse desafio e começou uma articulação para o fortalecimento da modalidade a distância junto às instituições que já ofereciam cursos à distância e a incentivar outras para que se iniciassem nessa modalidade" (PRETI, 2007, p. 2).

A UAB não é responsável por ofertar cursos, ou por realizar processo seletivo para ingresso no ensino superior, na verdade, ela é responsável por fazer “[...] seleção, matrícula, acompanhamento pedagógico, avaliação, estrutura de apoio, expedição de diploma, etc. como acontece nos seus cursos presenciais" (PRETI, 2007, p. 5). 
O sistema UAB foi estruturado para atender a nova demanda tecnológica dos cursos a distância, por isso foram elaborados os Ambientes Virtuais de Aprendizagem - AVA. Nesse contexto, a Coordenadoria de Aperfeiçoamento do Ensino Superior - CAPES, no comando do sistema Universidade Aberta do Brasil - UAB, em convênio com o Ministério da Educação MEC, estipulou um modelo de Ambientes Virtuais de Aprendizagem para cursos em universidades federais, a saber: o Modular Object-OrientedDynamic Learning Environmen Moodle. Segundo Provenzano, essa plataforma AVA é

[...] um ambiente de aprendizagem que propicia a interatividade e se insere em uma nova concepção de web, todavia, se não for utilizado no seu potencial, continuará reproduzindo a linearidade dos processos pedagógicos presenciais em uma perspectiva tradicional. Com a emergência da web 2.0 (chats, webconferência, fóruns, lista de discussão, blogs, wikis, facebook, dentre outros), no início do século XXI, há uma demanda por uma docência dialógica tanto no ambiente presencial quanto no ambiente on-line (PROVENZANO, 2013, p. 56).

A experiência com os ambientes virtuais possibilitou a criação e implantação de inúmeros cursos de extensão, graduação e pós-graduação em nível Latu Sensu, sendo que de 2000 a 2008 houve um crescimento quantitativo no número de cursos ofertados em todo o país. O Censo 2009 apontou que, das matrículas realizadas na modalidade a distância, 50\% são nos cursos de licenciatura e $26 \%$ nos de bacharelado. O curso de pedagogia detém $34 \%$ das matrículas (286.771 alunos matriculados), já o de administração tem 27\% (228.503 alunos matriculados), o de serviço social tem 8,1\% (68.055 alunos matriculados), o de letras 5,9\% (49.749 alunos matriculados) e o de ciências contábeis possui 3,6\% (29.944 alunos matriculados), entre outros. Diante desses números, percebe-se que a maior oferta é a de formação de professores para a educação básica, atendendo principalmente aqueles professores que estão em sala de aula, mas não possuem ensino superior (INEP, 2010).

A Educação a Distância é uma modalidade de ensino cujos recursos metodológicos baseiam-se nas esferas das diversas Tecnologias de Informação e Comunicação - TIC's, e cuja distância entre educando e educador é doravante separada temporal e espacialmente. Partindo da premissa exposta no art. 80 da Lei de Diretrizes e Bases da Educação Nacional, deverá “[...] o Poder Público incentivar o desenvolvimento e a veiculação de programas de ensino a distância, em todos os níveis e modalidades de ensino, e de educação continuada" (BRASIL, 1996, p. 1).

O Decreto $\mathrm{n}^{\circ}$ 5.622, em seu art. 30, apregoa que a educação básica deve ser tratada, obrigatoriamente, por parte do poder público, levando em consideração as normas previstas na 
lei como: utilizar uma abordagem emancipatória, bem como a ideia de uma educação que transcenda as barreiras de tempo, de espaço e de oportunidades (BRASIL, 2005).

Lopes et. al. (2010, p. 195) esclarece que, no Brasil, a Educação a Distância teve um crescimento significativo de aproximadamente 1,2 milhão de pessoas matriculadas nos cursos a distância em 2005 “[...] das quais, 504.204 estudaram em uma instituição autorizada pelo Sistema de Ensino Brasileiro. Junto a essa proliferação, assistimos também à multiplicação dos tipos de curso". Segundo a mesma autora, dados do Anuário Brasileiro Estatístico de Educação Aberta a Distância - ABRAEAD mostram que em 2005 foram ofertados 321 novos cursos, mais de $200 \%$ acima dos que foram ofertados em 2004, ano em que foram ofertados 56 novos cursos. Isso porque o número de instituições que se credenciaram para ofertar a Educação a Distância no país teve um crescimento de 30\%, passou de 166 para 217 instituições de ensino.

Em 2017, de acordo Lima (2019, p.2), houve um recorde de matriculados na EaD, cerca de 7.773.828, "[...] um crescimento de 17,6\% de 2016 para 2017. Os alunos dessa modalidade são quase 1,8 milhão, ou 21,2\% do total de matriculados em todo o Ensino Superior”. A Educação a Distância é oferecida com expressividade pelas instituições públicas e privadas em diferentes localidades do país. A tendência é aumentar, pois, em 2020, cerca de “[...] 50,7\% (1.559.725) dos alunos que ingressaram em instituições privadas optaram por cursos de EaD. Em contrapartida, 49,3\% (1.514.302) dos estudantes escolheram ingressar na educação superior de modo presencial (INEP, 2020, p. 1).

O ensino remoto ganhou destaque sobretudo após o surgimento da pandemia de Covid$19^{1}$, que obrigou o sistema educacional a interromper suas atividades presenciais e a se reinventar a fim de que fosse ofertado aos alunos o acesso aos conteúdos escolares. De acordo com Sathler (2020, p. 2), a pandemia desvelou um problema que já apresentava indícios de que precisaria de ações mais efetivas por parte dos docentes. $\mathrm{O}$ autor esclarece:

As aulas remotas em regime emergencial COVID-19 explicitam de forma inequívoca
uma realidade já sabida. Algo que antes estava meio turvo entre as paredes das escolas
e das salas de aula ou sob atenção de poucos. [...] O que vemos hoje com maior clareza
é algo que já gritava em frente aos nossos olhos. A Crise de Aprendizagem e a
desigualdade de acesso às TIC não são problemas novos.

A crise que se instaurou na educação, independentemente do nível de ensino, trouxe o debate sobre o acesso às tecnologias da informação e à comunicação na educação, pois, com o

\footnotetext{
1“'A COVID-19 é uma doença infecciosa causada pelo novo coronavírus (SARS-CoV-2) e tem como principais sintomas febre, cansaço e tosse seca. Uma em cada seis pessoas infectadas por COVID-19 fica gravemente doente e desenvolve dificuldade de respirar". (OPAS, 2021, p.1).
} 
distanciamento social, as famílias tiveram de se trancar em casa para não serem infectadas com o coronavírus, contudo, muitos alunos, por falta de recursos como celular, computador e internet, não tinham meios de continuar os estudos. "A pandemia impôs o distanciamento social a mais de 1,5 bilhão de estudantes e 63 milhões de professores em todo o mundo, que ficaram impedidos de frequentar os espaços físicos de escolas e instituições de educação superior" (SATHLER, 2020, p.1).

Para Vianney e Paranhos (2012, p. 1), não somente o sistema de ensino teve que se reinventar, mas todos os envolvidos no cenário educacional, pois houve a necessidade de desenvolver meios, mediados por tecnologia, para promover os encontros entre os professores e alunos em tempo real e/ou pelas " [...] chamadas de aulas remotas, ou de aulas conectadas, bem como de atividades de aprendizagem tais como sessões de reforço, atendimentos de inclusão, apresentações de trabalhos, momentos culturais ou de integração, entre outros". Os autores apresentam, além disso, algumas características das atividades conectadas:

1 - Professores e alunos com Aulas ao vivo - ou Aulas Remotas; ou Aulas Conectadas;

2 - Alunos e professores com Atividades síncronas e/ou assíncronas;

3 - Plataforma para a realização das aulas ao vivo;

4 - Ambiente Virtual de Aprendizagem (único ou integrado com a Plataforma) para o registro e memória da execução do Plano de Ensino, preservando de todas a aulas, frequências, atividades, entregas, tira-dúvidas, reforço e avaliações (VIANNEY; PARANHOS, 2012, p. 2).

As dificuldades enfrentadas neste momento excepcional poderiam ter outros rumos se tivessem sido consideradas quando o Ministério da Ciência, Tecnologia e Inovação alertou acerca da necessidade de mudança na educação em meio a uma sociedade em transformações tecnológicas. Assim:

Educar em uma sociedade da informação significa muito mais que treinar pessoas para o uso das tecnologias de informação e comunicação: trata-se de investir na criação de competências suficientemente amplas que lhes permitam ter uma atuação efetiva na produção de bens e serviços, tomar decisões fundamentadas no conhecimento, operar com fluência os novos meios e ferramentas em seu trabalho, bem como aplicar criativamente as novas mídias, seja em usos simples e rotineiros, seja em aplicações mais sofisticadas (BRASIL, 2000, p.45).

Percebe-se que havia desde os anos 2000 o entendimento da necessidade de "[...] formar os indivíduos para 'aprender a aprender', de modo a serem capazes de lidar positivamente com a contínua e acelerada transformação da base tecnológica" (BRASIL, 2000, p.45).

A mudança deveria ocorrer desde o currículo escolar - “[...] as discussões e as experiências de produção eletrônica de conhecimento propiciadas pela Internet têm muitas 
implicações para o conhecimento que ensinamos nas escolas", pois o uso da internet abre um leque de possibilidades para o desenvolvimento de atividades pedagógicas e de habilidades de lidar com novas problemáticas emergentes na sociedade, que têm na tecnologia seus indicadores de soluções, como os empregos no formato home office (DA SILVA, 2010, p.109).

Almeida et al. (2017, p. 393) corrobora com o entendimento de que há necessidade de mudanças efetivas na escola e que:

[...] a disseminação do uso das TDIC, o vertiginoso avanço da ciência e as transformações sociais fazem com que o referencial sobre currículo assuma novas características e se apresente com uma multiplicidade de referências e orientações teóricas e metodológicas. Surgem, assim, as propostas curriculares multi, inter e transdisciplinares, que permitem compreender e tratar do currículo contextualizado e multirreferencial, que se concretiza na prática social pedagógica e cultural ao incorporar os elementos do cotidiano trazidos pelas experiências de professores, professoras, alunos e alunas nas distintas redes de interação das quais participam, desenvolvem e aprendem.

O uso da educação na modalidade remota e/ou conectada emergiu de um contexto de pandemia para nos mostrar que as transformações educacionais são necessárias, mas estas devem ser aliadas às políticas públicas de minimização da desigualdade social no país, pois não adianta mudar o currículo e utilizar tecnologia nas escolas se muitos alunos não têm nem o que comer em casa.

Diante disso, depreende-se que o problema educacional não está dissociado das amarras sociais e deve ser considerado em um contexto amplo que carece de transformação situacional e que é direito do cidadão. "As reações indignadas à triste imagem da educação que o espelho digital insiste em nos mostrar podem se tornar o germe de uma transformação que é urgente, necessária e precípua à construção de um futuro menos impregnado de um passado marcado pela desigualdade" (DA SILVA, 2010, p.109).

\section{O DESAFIO DA EDUCAÇÃO BÁSICA NA MODALIDADE REMOTA}

O ensino remoto está sendo um grande desafio para a escola e para a família, pois sua adaptação não aconteceu progressivamente e sim da noite para o dia, em uma brusca aceitação. A Associação Brasileira de Educação a Distância (ABED) destaca que a adaptação a esse novo modelo educacional não tem sido fácil, visto que “[...] $67 \%$ dos alunos se queixam de dificuldades em estabelecer e organizar uma rotina diária de estudos, [...] 72,6\% consideram que o estudo remoto é pior na comparação com as aulas presenciais" e 51,5\% dos pais e/ou responsáveis, acreditam ser a pior forma de ensino ofertado no Brasil (OKUMURA, 2020, p. $1)$. 
Por parte dos alunos, as dificuldades envolvem desde a falta de habilidade com o manuseio da tecnologia, até problemas emocionais, solidão, saudade da escola, sociabilidade, entre outros. Em diferentes pesquisas surgem os indícios de como está sendo difícil suportar a carga educacional do sistema remoto. Okumura (2020, p.1) cita o caso de Izabelly Correia de Oliveira, de 16 anos, que teve crises de ansiedade depois que as escolas fecharam. As dúvidas são frequentes no caso dessa aluna, pois ela não conseguia se organizar e "“[...] entender quando é momento de assistir a aula e não fazer outra coisa. Tentar organizar minha rotina de estudos e também não me dispersar durante as atividades".

Para Zanfolin (2020), os desafios que fazem parte deste cenário começam quando as crianças são obrigadas a ficarem em casa e estabelecerem uma rotina de estudo e de vida. A autora conta o caso de Laura, de 10 anos, cujos pais e/ou responsáveis, que não ficavam em casa porque tinham uma rotina grande de trabalho, notaram que a filha, que era muito estudiosa, se apresentava desanimada, não queria fazer as atividades e nem assistir às aulas remotas. A mudança no comportamento preocupou os pais, pois, para eles, não era comum ver Laura agindo de tal maneira.

Acredita-se que as crianças não estão preparadas para serem autônomas, para estabelecerem rotina e terem participação no processo educativo, já que antes sempre contavam com alguém que fizesse isso por elas - professores, pais e responsáveis.

Em análise dos principais provedores da internet, periódicos e jornais online, encontramos inúmeros depoimentos que comprovam o despreparo do país para estabelecer um ensino básico a distância e/ou remoto, tal como podemos perceber no quadro a seguir:

Quadro 2 - Depoimentos de estudantes na internet

\begin{tabular}{|c|c|c|}
\hline Site & Opinião & Estudante \\
\hline Folha BV & $\begin{array}{l}\text { "Me senti desmotivada por sentir falta das relações } \\
\text { sociais que eu tinha com alunos, professores e } \\
\text { funcionários da escola, sem contar que a qualidade } \\
\text { de ensino caiu bastante com esse distanciamento } \\
\text { nosso da sala de aula presencial." }\end{array}$ & $\begin{array}{c}\text { Estudante - Ensino } \\
\text { Fundamental }\end{array}$ \\
\hline Folha BV & $\begin{array}{l}\text { "Me senti um pouco desmotivada, apesar de eu } \\
\text { sempre ter sido uma aluna esforçada. Tenho } \\
\text { dificuldades de assimilar o estudo em casa, é bem } \\
\text { difícil, na escola é mais fácil por todo o apoio, } \\
\text { inúmeras vezes pensei em desistir." }\end{array}$ & $\begin{array}{c}\text { Estudante - Ensino } \\
\text { Médio }\end{array}$ \\
\hline Lance notícias & $\begin{array}{l}\text { "A falta de um professor explicando pessoalmente, } \\
\text { pois, a distância, sempre acabam surgindo dúvidas } \\
\text { que, muitas vezes, acabam ficando sem resposta, }\end{array}$ & $\begin{array}{c}\text { Estudante - Ensino } \\
\text { Fundamental }\end{array}$ \\
\hline
\end{tabular}




\begin{tabular}{|c|c|c|}
\hline & $\begin{array}{l}\text { hora por vergonha ou até falta de interesse do aluno } \\
\text { em aprender determinado assunto". }\end{array}$ & \\
\hline Folha UOL & $\begin{array}{l}\text { "A minha experiência está sendo mais ou menos. É } \\
\text { um pouco ruim porque a tia não me responde } \\
\text { [como antes]" }\end{array}$ & $\begin{array}{l}\text { Estudante - Ensino } \\
\text { Fundamental }\end{array}$ \\
\hline Folha UOL & $\begin{array}{l}\text { "Tem sido bem difícil. Eu não gosto de falar em } \\
\text { sala, então nunca consigo nota de participação, } \\
\text { nem apresentar trabalhos, o que prejudica muito as } \\
\text { minhas notas e me desmotiva um pouco [...]." }\end{array}$ & $\begin{array}{l}\text { Estudante - Ensino } \\
\text { Fundamental }\end{array}$ \\
\hline Folha de São Paulo & $\begin{array}{l}\text { "Agora, os professores colocam lições com uma } \\
\text { quantidade parecida com o número de aulas que } \\
\text { eles terão na semana. Antes, tinha dias que eu } \\
\text { passava o dia todo estudando quando o certo seria } \\
\text { ficar cinco horas." }\end{array}$ & $\begin{array}{l}\text { Estudante - Ensino } \\
\text { Médio }\end{array}$ \\
\hline Lance notícias & $\begin{array}{l}\text { "As dificuldades que tenho por aulas a distância é } \\
\text { que, muitas vezes, não é fácil de entender o } \\
\text { conteúdo, pois a explicação em sala de aula era } \\
\text { muito melhor, e também que aqui onde moro não } \\
\text { tem internet todos os dias; por isso, dificulta a } \\
\text { entrega dos trabalhos e a participação das aulas on- } \\
\text { line." }\end{array}$ & $\begin{array}{l}\text { Estudante - Ensino } \\
\text { Médio }\end{array}$ \\
\hline Lance notícias & $\begin{array}{l}\text { "As maiores dificuldades é apreender, entender. } \\
\text { Ficamos } 14 \text { anos aprendendo no modo clássico, } \\
\text { dentro de sala de aula, onde é mais fácil discutir } \\
\text { com o professor, não que aqui seja ruim, mas não é } \\
\text { da mesma forma. Por mais que temos auxílio da } \\
\text { internet, mesmo assim não é fácil. Nós nos } \\
\text { sobrecarregamos, com tantos trabalhos e } \\
\text { informações que estamos recebendo." }\end{array}$ & $\begin{array}{l}\text { Estudante - Ensino } \\
\text { Médio }\end{array}$ \\
\hline
\end{tabular}

Fonte: Diferentes jornais online (2019-2021).

Por meio dos depoimentos dos alunos, nota-se que há muitos limites a serem superados para que a educação básica possa galgar, com qualidade, as trilhas da Educação a Distância, pois, quando se fala que a qualidade caiu, há uma grande preocupação, visto que a qualidade da educação básica se constitui como um dos principais problemas educacionais a ser superado no Brasil. Quando se fala em qualidade na educação remota, fala-se da falta de sistematização do ensino, da realização de atividades soltas e sem objetivo estabelecido, podendo o aluno executar a tarefa de qualquer jeito e mesmo assim obter nota, nesse cenário, não é a aprendizagem que é levada em consideração, mas sim o fato de realizar a atividade para constar nos arquivos.

Com frequência, os alunos destacam as dificuldades de assimilar o estudo; acredita-se que talvez seja pela falta de um ambiente propício para realizá-lo, ou por haver muitas pessoas em casa, ou simplesmente porque o aluno está em casa. A casa, no imaginário dos educandos, 
não é a escola, não é o local de estudar o tempo todo e sim de assistir TV, brincar etc. Por isso, a falta de concentração nas aulas pode acontecer de maneira que atrapalhe os estudos dos alunos. Além disso, em muitos casos, enquanto o aluno estuda, os pais trabalham, os irmãos correm e brincam, tudo acontece ao mesmo tempo.

Outro problema enfrentado pelos estudantes é o fato de que muitas vezes o aluno não entende o conteúdo e não pergunta, ou por vergonha ou por medo. Nessa nova circunstância, os mesmos não perguntam sobre o conteúdo nas aulas porque seus microfones ficam desabilitados. Essa situação faz parecer que o ciclo de problemas sempre retorna em momentos diferentes, de modo que a chamada "falta de domínio de sala" - um clichê no modelo presencial - pode acabar invadindo também as aulas remotas.

A tecnologia é uma aliada, mas quem comanda é o professor. Ele pode abrir e fechar os microfones dos alunos a hora que determinar, sem que seja necessário um silenciamento. Essa prática pode fazer emergir novamente a educação tradicional - em que o professor é o cerne do conhecimento. Nesse modelo, o educador deposita os conteúdos a serem arquivados pelos alunos, dessa forma "[...] a educação se torna um ato de depositar, em que os educandos são os depositários e o educador o depositante. Em lugar de comunicar-se, o educador faz "comunicado" e depósitos que os educandos, meras incidências, recebem pacientemente, memorizam e repetem" (FREIRE, 2000, p. 58).

As virtualidades, de acordo com Barton e Lee (2015, p. 45), são conhecimentos construídos no social e "[...] mudam à medida que as pessoas atuam, sobre seu ambiente. As virtualidades afetam o que pode ser feito facilmente e o que pode ser feito convencionalmente com um recurso [...], assim, as virtualidades emergem o tempo todo, e novas possibilidades são criadas pela criatividade humana.

Quando novas práticas democráticas são iniciadas, leva-se um tempo para que os alunos aprendam a lidar com os acordos estabelecidos, por isso, se o professor estabelece que deixará por conta do aluno a responsabilidade do microfone e da câmera, este pode até errar algumas vezes, mas logo aprenderá a utilizar o mecanismo como se deve, ou a utilizar o sistema de clicar no dispositivo e levantar a mão virtual. Esse sistema está presente em plataformas unificadas de comunicação como o Google Meet e o Teams. Nesse sentido, o professor deve sempre lembrar que todos somos seres sociais, “[...] histórico, como ser pensante, comunicante, transformador, criador, realizador de sonhos, capaz de ter raiva porque é capaz de amar. 
Assumir-se como sujeito porque é capaz de reconhecer-se como objeto. A assunção de nós mesmos não significa a exclusão dos outros” (FREIRE, 2001, p.46).

A falta de habilidade e de conhecimento em relação ao manuseio da tecnologia não pode ser motivo para o retorno de velhos problemas. O ensino remoto tem muitos limites, alguns inclusive partem dos próprios professores, mas há muitos modos de ensinar e aprender, como nos mostra o caso de Helivania Sardinha, uma professora do ensino fundamental e médio, entrevista pelo Brasil Escola para falar das vantagens e desvantagens de trabalhar em casa. Ela conta que, no início da pandemia, utilizou diferentes redes sociais e ferramentas tecnológicas para a aula ao vivo, como o Google Classroom e os grupos de Whatsapp, mas a câmera a deixava incomodada: "Sobre as novas tecnologias utilizadas, por exemplo, eu posso citar o fato de que muitas pessoas têm facilidade em falar com multidões, mas falar para uma câmera é algo totalmente diferente e desafiador" (BRASIL ESCOLA, 2020, p. 1).

Em sala de aula, na escola, o professor é o responsável pelos andamentos da aula, é seu lugar restrito, sua zona de conforto, na qual ele determina os limites de seu trabalho e posicionamento pedagógico. Em contrapartida, ministrar aula de frente para uma câmera é algo incerto, sem controle, algo que foge à governabilidade do docente, pois é o aluno que decide estar ali ou não. Os papéis se invertem nesse momento transitório, muitos professores reclamam que o aluno entra na sala de aula virtual, deixa a câmera fechada, mas não está assistindo a aula.

O professor Rafael Victor aponta outra questão: “Como eu não estava acostumado com esse tipo de trabalho, tive que aprender a utilizar muitas ferramentas, sem falar que o formato das atividades feitas a distância é bastante diferente das feitas em sala de aula e isso é bastante desafiador" (BRASIL ESCOLA, 2020, p. 1). A fala do professor Rafael suscita reflexões sobre como os professores tiveram de se reinventar nesse momento de pandemia, pois muitos não tinham conhecimento de como utilizar a tecnologia em suas aulas, o que dificultou o início das atividades remotas. Contudo, apesar dessas dificuldades, podemos dizer que a tecnologia não é uma inimiga, mas uma verdadeira aliada da ação pedagógica em sala, se bem empregadas, podem potencializar as aulas, tornando-as mais dinâmicas e atrativas.

A EaD se configura como uma "[...] modalidade educacional na qual a mediação didático-pedagógica nos processos de ensino e aprendizagem ocorre com a utilização de meios e Tecnologias da Informação e Comunicação, com estudantes e professores desenvolvendo atividades educativas em lugares ou tempos diversos (BRASIL, 2005, p.1). Ambos estão ligados pelo ato educativo e podem se comunicar a hora que houver necessidade. Essa confusão 
de informações, talvez, venha dificultando as decisões dos professores no momento de realização do planejamento da aula. Nesse contexto, surge, portanto, a necessidade de diferenciarmos aulas $\mathrm{EaD}$ de aulas remotas:

Quadro 3 - Diferença entre aulas remotas e EaD's

\begin{tabular}{|l|l|}
\hline \multicolumn{1}{|c|}{ Aula remota } & \multicolumn{1}{|c|}{ Aula EAD } \\
\hline $\begin{array}{l}\text { Aula ao vivo ou gravada nos dias e horários da } \\
\text { presencial; }\end{array}$ & Videoaulas gravadas; \\
\hline Interação com o seu professor da disciplina; & Único tutor para tirar dúvidas; \\
\hline $\begin{array}{l}\text { Materiais personalizados e elaborados pelo } \\
\text { professor da disciplina; }\end{array}$ & $\begin{array}{l}\text { Materiais e atividades padronizados, } \\
\text { produzidos em escala; }\end{array}$ \\
\hline $\begin{array}{l}\text { Calendário próprio, de acordo com plano de } \\
\text { ensino, adaptado para a situação emergencial; }\end{array}$ & $\begin{array}{l}\text { Calendário letivo padronizado } \\
\text { unificado; }\end{array}$ \\
\hline $\begin{array}{l}\text { Avaliações e testes personalizados, criados } \\
\text { pelo professor da disciplina, conforme } \\
\text { conteúdo abordado nas aulas remotas. }\end{array}$ & $\begin{array}{l}\text { Avaliações e testes padronizados, } \\
\text { produzidos e corrigidos em escala. }\end{array}$ \\
\hline
\end{tabular}

Fonte: UNITAU (2020).

De posse dessas informações, o docente conseguirá compreender como cada tipo de ensino pode ser planejado. O momento educacional está sendo muito difícil tanto para os alunos quanto para os professores, mas a grande parcela de responsabilidade pelo ato educacional fica nas mãos de quem está no "chão da sala de aula" e, nesse lugar, os erros podem interferir na vida de muitas crianças em formação. Por isso, devemos estar atentos às novas mudanças educacionais, aos usos de recursos pedagógicos que tenham como a tecnologia como uma aliada e a busca de formação continuada para o aprimoramento do docente.

O momento pandêmico trouxe não só desafios de ensino e aprendizagem, mas sobrecarga de trabalho e decisões para os docentes. Estes tiveram de ser reinventar para atender as demandas educacionais, sem muitas vezes saberem utilizar o computador e a internet. São novos tempos e novos desafios para a educação básica, porém, vale dizer que essas novidades podem abrem inúmeras possibilidades, pois quando voltarmos ao ensino presencial, certamente, o aprendizado adquirido nesse período poderá ser utilizado para enriquecer o fazer pedagógico em sala de aula.

\section{CONSIDERAÇõES FINAIS}

A presente pesquisa mostrou que ainda estamos caminhando para mudanças significativas na educação básica e que esta não está estruturada para se realizar na modalidade 
$\mathrm{EaD}$ ou remota. Ainda há muito a se buscar para vencer as barreiras, principalmente de qualidade educacional, que entravam tais modalidades de ensino.

A educação remota surgiu em função de uma necessidade emergencial e deve ser considerada com seriedade, pois conferiu à docência novos contornos, atribuições e responsabilidades educacionais, transformando o cotidiano de pais e/ou responsáveis, alunos e professores.

Nesse novo contexto, a tecnologia foi fundamental para que os alunos não ficassem sem as atividades escolares. De um lado, ela impôs dificuldades, mas, de outro, trouxe benefícios, por isso, é hora de estruturar o conteúdo, deixar o círculo queixoso, e sobretudo buscar o melhoramento profissional. Existem pessoas que não atribuem mudanças à educação, mas nesse caso não há como negar as transformações eminentes - quase $100 \%$ dos docentes da rede pública e privada tiveram suas vidas mudadas e agora estão aptos a trabalhar com a Educação a Distância. Toda essa experiência, sem dúvida, poderá transformar profundamente a educação brasileira.

\section{REFERÊNCIAS}

BARTON, David; LEE, Carmen. Aprender online todos os dias. In. Linguagem online: textos e práticas digitais. Tradução de Milton Camargo Mota. São Paulo: Parábola Editorial, 2015. 165-182.

BRASIL ESCOLA. Coronavírus: Professores falam dos desafios e vantagens de trabalhar em casa. 2000. Disponível em: https://educador.brasilescola.uol.com.br/noticias/coronavirusprofessores-falam-dos-desafios-e-vantagens-de-trabalhar-em-casa/33270.html. Acesso em: $16 / 05 / 2021$.

BRASIL. Decreto no 5.622, de 19 de dezembro de 2005. Disponível em: http://portal.mec.gov.br/seed/arquivos/pdf/dec_5622.pdf. Acesso em 02/05/2020.

BRASIL. Lei de Diretrizes e Bases da Educação Nacional, LDB. 9394/1996 São Paulo: Saraiva.

BRASIL. Ministério da Ciência e Tecnologia. Sociedade da informação no Brasil: Livro Verde. TAKAHASHI, Tadao(Org). Brasília: Ministério da Ciência e Tecnologia, 2000. Disponível em: http://www.inst-informatica.pt/servicos/informacaoedocumentacao/biblioteca-digital/gestao-e-organizacao/BRASIL_livroverdeSI.pdf. Acesso em: 16/05/2021.

DA SILVA, Luiz Henron. A Escola no contexto da globalização. 15. ed. Rio de Janeiro: Editora Vozes, 2010. 
FOLHA BV. Alunos relatam dificuldades em se adaptar ao ensino remoto. 2020. Disponível em: https://folhabv.com.br/noticia/CIDADES/Capital/Alunos-relatamdificuldades-em-se-adaptar-ao-ensino-remoto/70602. Acesso em: 16/05/2021.

FREIRE, Paulo. Pedagogia da Autonomia. Saberes necessários à prática educativa. São Paulo: Paz e Terra, 2001.

FREIRE, Paulo. Pedagogia do Oprimido. Editora Paz e Terra, 29a.Edição, 2000.

HERNANDES, Paulo Romualdo. A Universidade Aberta do Brasil e a democratização do Ensino Superior público. Ensaio: aval. pol. públ. Educ., Rio de Janeiro. (Fundação Cesgranrio. Impresso), p. 1-25, 2017. Disponível em:

https://www.scielo.br/pdf/ensaio/2017nahead/1809-4465-ensaio-S010440362017002500777.pdf. Acesso em: 30/04/2020.

INEP. Ensino a distância se confirma como tendência. Censo da educação superior. 2020. Disponível em: https://www.gov.br/inep/pt-br/assuntos/noticias/censo-da-educacaosuperior/ensino-a-distancia-se-confirma-como-tendencia. Acesso em: 16/05/2021.

LANCE NOTÍCIAS. Aulas remotas: desafios enfrentados por professores e alunos. 2020. Disponível em: https://lancenoticias.com.br/noticia/aulas-remotas-desafios-enfrentados-porprofessores-e-alunos. Acesso em: 16/05/2021.

LIMA, Cláudia de Castro Educação a distância: um modelo que só cresce. 2019. Disponível em: https://forbes.com.br/negocios/2019/03/educacao-a-distancia-um-modelo-que-so-cresce/. Acesso em: 01/07/2021.

LOPES, Maria Cristina Lima Paniago; SALVAGO, Blanca Martin; PISTORI, Jeferson; DORSA, Arlinda Cantero; Almeida, Dea Terezinha Rimoli. Educação a distância no ensino superior: uma possibilidade concreta de inclusão social. Revista Diálogo Educacional (PUCPR), v. 10, p. 191-204, 2010. Disponível em:

https://periodicos.pucpr.br/index.php/dialogoeducacional/article/view/3088/3016. Acesso em 03/05/2020.

MILL, Daniel; FIDALGO, Fernando. Sobre tutoria virtual na Educação a Distância: caracterizando o teletrabalho docente. In: Virtual Educa, 2007. Disponível em: http://ihm.ccadet.unam.mx/virtualeduca2007/pdf/236-DM.pdf. Acesso em: 01/05/2020.

MOORE, Michael G, KEARSLEY, Greg. Distance education: a systems Wiew. Belmont, MORAN, José. O que é educação a distância. 2013. Disponível em: http://www2.eca.usp.br/moran/wp-content/uploads/2013/12/dist.pdf. Acesso em: 01/07/2021.

OKUMURA, Renata. Durante a pandemia, $67 \%$ dos alunos têm dificuldade para organizar estudos online. 2020. Disponível em: https://educacao.uol.com.br/noticias/agencia-estado/2020/10/30/durante-a-pandemia-67-dosalunos-tem-dificuldade-para-organizar-estudos-online.htm?cmpid=copiaecola. Acesso em: $16 / 05 / 2021$. 
OPAS. Folha informativa sobre o COVID 19. Organização Pan-americano de Saúde. 2021. Disponível em: https://www.paho.org/pt/covid19. Acesso em: 02/05/2021.

PRETI, Oreste. A Universidade Aberta do Brasil: uma política de Estado para o ensino superior "a distância", 2007. Disponível em: https://setec.ufmt.br/uploads/files/pcientifica/uab politica de estado.pdf. Acesso em 03/05/2020.

PROVENZANO, Maria Esther. A Mediação docente sob o olhar dos cursistas. In: Ead, tecnologias e TIC / Wilson Massashiro Yonezawa, Daniela Melaré Vieira Barros (organizadores). - São Paulo: Cultura Acadêmica; Marília: Oficina Universitária, 2013. Disponível em: https://www.marilia.unesp.br/Home/Publicacoes/af-livro_12 barros-v2.pdf. Acesso em: 01/07/2021.

SARAIVA, Karla; TRAVERSINI, Clarice; LOCKMANN, Kamila. A educação em tempos de COVID-19: ensino remoto e exaustão docente. Práxis Educativa, Ponta Grossa, v.15, e2016289, p. 1-24, 2020. Disponível em:

<https://revistas.apps.uepg.br/index.php/praxiseducativa/article/view/16289/209209213529>. Acesso em: 30/06/2021.

SATHLER, Luciano. O espelho digital na educação. 2020. Disponível em: http://abed.org.br/arquivos/espelho_digital_ead_luciano_sathler.pdf. Acesso em 02/05/2021.

UNIPAMPA, Universidade Federal de Pampas. Divisão de Educação a Distância, 2014. Disponível em: https://sites.unipampa.edu.br/ead/uab-universidade-aberta-do-brasil. Acesso em 02/05/2021.

UNITAU. A diferença entre a aula remota e a aula EAD. 2020. Disponível em: https://unitau.br/noticias/detalhes/4281/entenda-a-diferenca-entre-a-aula-remota-e-a-aula-ead. Acesso em 02/05/2021.

VIANNEY, João; PARANHOS, Mayra Caiado. As Diferenças entre Ensino Conectado e a Educação a Distância na pandemia. 2012. Disponível em:

http://abed.org.br/arquivos/Ensino_Conectado_x_EAD_Vianney.pdf. Acesso em: 16/05/2021.

YONEZAWA, Wilson Massashiro; BARROS, Daniela Melaré Vieira (Orgs).Ead, tecnologias e TIC. São Paulo: Cultura Acadêmica; Marília: Oficina Universitária, 2013. Disponível em: https://www.marilia.unesp.br/Home/Publicacoes/af-livro_12_barros-v2.pdf. Acesso em: 01/07/2021.

ZANFOLIN, Thainá. Crianças cansadas e pais estressados: como lidar com o ensino remoto prolongado? 2020. Disponível em: https://cangurunews.com.br/ensino-remoto. Acesso em: 16/05/2021. 